B025

\title{
METALLACROWNS: \\ A NEW CLASS OF METAL BINDING AGENTS
}

Vincent L. Pecoraro, Myoung Soo Lah, Dimitris P. Kessissoglou, Jeff Kampf and Brian Gibney. Department of Chemistry, University of Michigan, Ann Arbor, MI 48109-1055 USA

Metal sequestration by agents such as crown ethers [1], siderophores [2] and polyaminocarboxylic acids have been studied extensively. We have commented [3] on a new class of molecules, metallacrowns, that may present a unique way to generate in a controlled manner unique homo- and heterometallic clusters. The metallacrowns structurally resemble crown ethers in that they form cyclic structures that orient multiple, formally neutral,

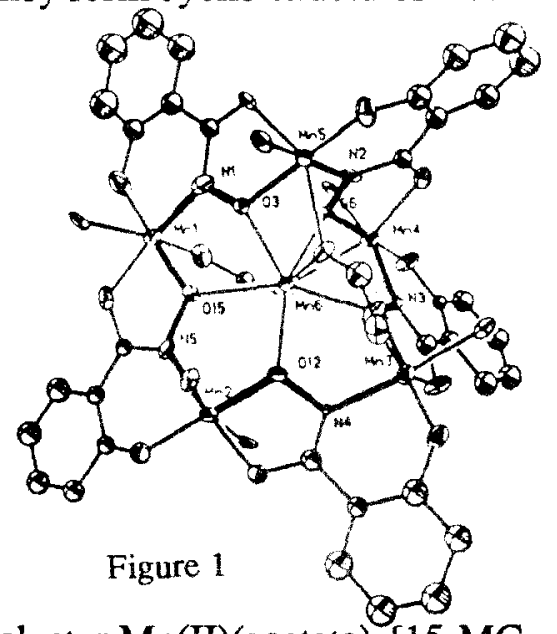

oxygen atoms into a cavity that can capture a free metal ion. However, unlike crown ethers, metallacrowns form $9-12$ - or $15-$ membered rings using only heteroatom linkages such as $-\left[-\mathrm{Mn}(\mathrm{III}) \mathrm{NO}^{-}\right]_{4}$. The metallacrowns also are related to siderophores in that the primary functional groups that bind the ring metals are hydroxamic acids, specifically salicylhydroxamic acid. Two examples of metallacrowns are illustrated. The hexanuclear, mixed valence man-

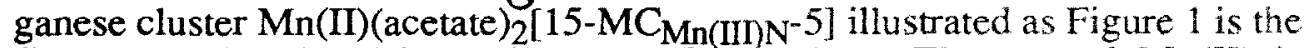
first example of a 15-metallacrown-5 complex. The central $\mathrm{Mn}$ (II) is encapsulated by five hydroximate oxygen atoms of the ring and two acetate oxygens. Metallacrowns can also be fused to make mixed metal metallacryptates such as $\mathrm{Na}_{2}\left[\mathrm{Na}\left\{\left[12-\mathrm{MC}_{\mathrm{Ga}}\left(\mathrm{IInN} \mathrm{N}^{-4}\right]_{2}(\mu-\mathrm{OH})_{4}\right\}\right]\right.$ as illustrated in Figure 2. A Na(I) ion is complexed by two fused [12-MC $\left.\mathrm{Ga}(\mathrm{III}) \mathrm{N}^{-4}\right]$ clusters. We will present $1 \mathrm{H}$ NMR data that demonstrates that the central metals of metallacrowns can be exchanged while retaining the metallacrown ring. We will also discuss the competition of crown ethers with metallacrown ethers for the captured central ion.

Figure 2

1. C.J. Pedersen, J. Amer. Chem. Soc., 89, 2495 (1967).

2. J.B. Nielands, ed. Microbial Iron Transport: A Comprehensive Treatise, Academic Press, New York (1974).

3. M.S. Lah and V.L. Pecoraro, Comments Inorg. Chem., 11, 59 (1990),

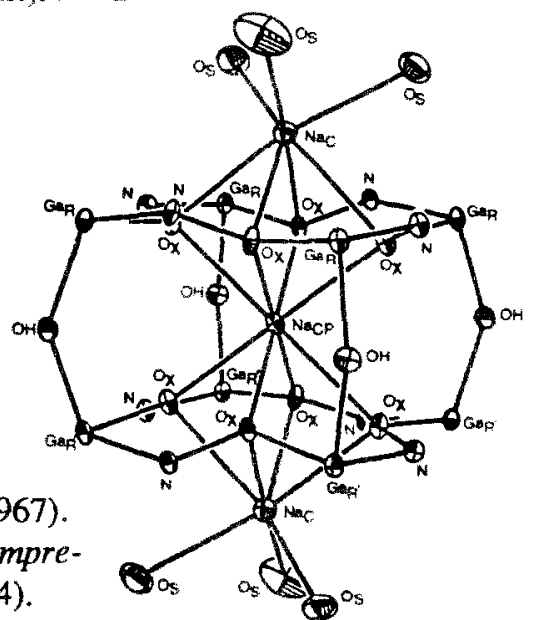

$C_{1}{ }_{\mathrm{s}}$ 